\title{
THE INFLUENCE OF HPC-L AND EUDRAGIT L30 D-55 ON DELAYED RELEASE OMEPRAZOLE MAGNESIUM MULTIPLE-UNIT PELLET SYSTEM
}

\author{
VARALAKSHMI MUMMIDI*,SHAIK REZWANA
}

School of Pharmaceutical Sciences and Technologies, Jawaharlal Nehru Technological University, Kakinada, East Godavari - 533 003, Andhra Pradesh, India. Email: vara148@gmail.com

Received: 03 February 2018, Revised and Accepted: 03 April 2018

\section{ABSTRACT}

Objective: The objective of the study is to develop optimum, stable, delayed release pellets of omeprazole magnesium (20.6 mg dose). Omeprazole magnesium is a proton pump inhibitor that suppresses gastric acid secretion by specific inhibition of the $\mathrm{H}^{+} / \mathrm{K}^{+}$ATPase at the secretory surface of the gastric parietal cell, which is orally administered drug, whereas omeprazole magnesium is degraded in stomach pH, so it is formulated as delayed release dosage form to absorb in intestinal $\mathrm{pH}$.

Methods: The formulation of delayed release pellets of omeprazole magnesium was developed by enteric film coating process varying the compositions of drug loading, barrier coating, and enteric coating using fluid bed processor. The prepared multiple pellets were filled into hard gelatin capsules as a single unit dosage forms.

Results: The dissolution profile of formulation (F8) contains the efficient amount of hydroxypropyl cellulose-L and Eudragit L30 D55 leads to effective release of drug in $30 \mathrm{~min}$. Fourier transform infrared and differential scanning colorimeter studies were conducted for the optimized formula to prove that the formula was not having incompatibility between the drug and excipients. The scanning electron microscopy studies were conducted to know the surface morphology of the pellets.

Conclusion: It was concluded that optimized formulation (F8) shown good similarity with innovator. The results of the accelerated stability of final formulation revealed that storage conditions were excellent.

Keywords: Delayed release, Enteric coating, Fluid bed processor, Pellets, Omeprazole magnesium.

(C) 2018 The Authors. Published by Innovare Academic Sciences Pvt Ltd. This is an open access article under the CC BY license (http://creativecommons. org/licenses/by/4. 0/) DOI: http://dx.doi.org/10.22159/ajpcr.2018.v11i7.25098

\section{INTRODUCTION}

Therapeutically, omeprazole, a typical proton pump inhibitor, has an irritant effect in the gastric environment and is unstable at the gastric $\mathrm{pH}$. To overcome this, enteric coating is required for active content to provide its proper therapeutic effect and pharmacological action. The proton pump is highly unstable at acidic $\mathrm{pH}$ of gastric environment and stable at intestine $\mathrm{pH} \geq 5.5$, so enteric coated tablets or pellets are prepared for the delayed release action $[1,2]$.

Several excellent reviews have provided different types of polymer coatings on drugs and use of plasticizers, stabilizers, solubilizers, film formers, and different approaches to overcome the stability problems and storage conditions. Polymers such as ethyl cellulose, cellulose acetate phthalate, hydroxypropyl methylcellulose (HPMC) phthalate, and methyl/ethyl acrylic acid copolymers (Eudragit series) were used as enteric film coatings for proton pump inhibitors. However, these polymers greatly influence the drug stability and bioavailability due to the interaction of the free carboxyl groups in enteric polymers and the drug. Among the polymers, Eudragit L 30D was the most widely used anionic copolymer in pharma industry. It is easily redispersed into water with the assistance of small amounts of organic base, resulting in redispersed latex at $\mathrm{pH} 2-3$, and ionized at $\mathrm{pH} \geq 5$ [3-5]. Low-substituted hydroxypropyl cellulose (L-HPC) was used as a binder and disintegrant in the powder layering process on spherical cores and to prepare pellets. Due to low particle size and high hydroxypropyl content, it is recommended to produce round spheres and rapid dissolution [6].

Chemically, omeprazole magnesium is 5-Methoxy-2-(( (4-methoxy-3,5dimethyl-2-pyridinyl)methyl)sulfinyl)-1H-benzimidazole magnesium salt (2:1) [2]. Omeprazole, an orally administered drug, is a proton pump inhibitor that suppresses gastric acid secretion by specific inhibition of the
$\mathrm{H}^{+} / \mathrm{K}^{+}$ATPase at the secretory surface of the gastric parietal cell [1]. It belongs to BCS class II drugs, which has poor solubility and high permeability. The dissolution problems of poorly water-soluble drugs have been largely solved to improve drug absorption and bioavailability using pelletization technique [3]. Pelletization technique is a unique and economical approach to overcome drug problems such as poor bioavailability that is related with the delivery of hydrophobic drugs, including those that are poorly soluble in aqueous as well as organic media [7]. The objective of the present study is to formulate and evaluate omeprazole magnesium delayed release pellets filled capsules using drug layering technique with fluid bed processor for the treatment of acidity and ulcers.

\section{MATERIALS AND METHODS}

\section{Materials}

Omeprazole magnesium was gift sample from Aurobindo Pharma Ltd., (Hyderabad, India). Sugar spheres USNF (250-300 $\mu \mathrm{m})$ procured from JRS Pharma (mfg) and Forum Product Pvt. Ltd. (supp); Hypromellose purchased from Signet Chemical Corporation (Mumbai, India); Polysorbate 80, HPC-L, Triethyl citrate, Glyceryl monostearate (Imwitor 900K), Magnesium stearate, and Sodium hydroxide (USNF grades) were purchased from Merck Ltd; Methacrylic acid copolymer dis (Eudragit L30 D55) was purchased from Shin-Etsu Chemical Co., Ltd. (Tokyo, Japan); Talc was procured from Luzenac Pharma Ltd. ( $\mathrm{mfg}$ ) and Signet Chemical Corporation (supp). All other chemicals used were of analytical grade.

\section{Methods}

Preformulation studies

Solubility studies

Solubility studies were carried out by preparing saturated solutions of omeprazole magnesium in various non-volatile solvents such 
as methanol, ethanol, acetone, isopropanol, and water and also to determine the solubility of drug in the solvents of purified water, $\mathrm{pH}$ 6.8, and $\mathrm{pH} 7.4$ phosphate buffer. An excessive amount of omeprazole magnesium was added in small incremental amounts to a fixed volume of the solvent (100 mL of water) with the system and sonicated it for $24 \mathrm{~h}$ at room temperature to ensure complete dissolution of the solute in the solvent. The saturated solutions were diluted, filtered, and analyzed by UV spectrophotometer (Shimadzu 2800, Japan) at $222 \mathrm{~nm}$.

Drug-excipient compatibility studies

Omeprazole magnesium was mixed with each excipient such as sugar spheres, Hypromellose, HPC-L, talc, magnesium stearate, $\mathrm{NaOH}$, Eudragit L30 D55, Triethyl citrate, imwitor K90, and polysorbate 80 in the ratio (1:0.5), and the mixture was sifted through \#40 and taken into glass vials. The blends are loaded into stability chamber at $2-8^{\circ} \mathrm{C}$ and $40^{\circ} \mathrm{C} / 75 \% \mathrm{RH}$ accelerated conditions for 4 weeks. After the specified period, blends are tested for impurity profile and physical change was observed to know the compatibility of the drug with excipients in open and closed environment.

\section{Formulation of delayed release omeprazole magnesium enteric coated pellets}

The following steps are involved in manufacturing process of enteric coated pellets $[8-10,27]$. The composition of each formulation and process-related parameters are summarized in Tables 1 and 2.

\section{Selection of inert core}

Sugar spheres are available in different sizes with uniformity. The dispensed sugar spheres were sifted through sieve \# 50 and \# 60, the retentions on \# 50 were discarded, and fines passed through \# 60 were selected for further development. Specified quantity of sugar spheres was accurately weighed and loaded into fluid bed processor bowl and pre-warm with an inlet temperature $45 \pm 10^{\circ} \mathrm{C}$ till bed temperature reaches $30 \pm 5^{\circ} \mathrm{C}$.

\section{Preparation of drug-layered pellets}

Specified quantities of hypromellose (HPMC E5) and talc were added in $60 \%$ and $20 \%$ of total required quantity of purified water into suitable container with stirrer. Polysorbate 80 was added in $5 \%$ of water and heated to $60^{\circ} \mathrm{C}$ under stirring to form a uniform suspension. Specified quantity of omeprazole magnesium was added slowly under stirring. Sugar spheres were coated with the prepared drug suspension using Fluidized Bed processor (Glatt, Mumbai). The weight gain after completion of spraying drug loading dispersion was checked, and the drug-loaded pellets were dried for not less than 15 min with low fluidization at a bed temperature of $35 \pm 5^{\circ} \mathrm{C}$. The drug-loaded pellets were screened through sieve \# 40 and \# 50, and the retentions on \# 40 and fines passed through \# 50 were discarded.

Preparation of subcoating pellets

Talc, magnesium stearate, and HPC-L were added in $60 \%$ of total required quantity of purified water under stirring into vortex to disperse uniformly, and the solution is passed through homogenizer. The solution is sprayed onto drug-loaded pellets until target weight of pellets was attained. The subcoated pellets were screened through \#30 and \#50, and the retentions on \#30 and fines passed through \#50 were discarded.

\section{Preparation of enteric coating pellets}

Polysorbate 80 and glyceryl monostearate were added in $20 \%$ of total required quantity of purified water and heated at $70^{\circ} \mathrm{C}$. Talc and triethyl citrate were added and stirred for $5 \mathrm{~min}$. The solution is poured into homogenizer and allowed to blend for 20 min to make a clear dispersion. Eudragit L30 D55 was added. The dispersion was screened through sieve \#80. The subcoated pellets were loaded into the fluid bed processor bowl and the dispersion was sprayed onto the pellets until target weight was attained. The enteric coated pellets were screened through \#30 and \#40, and the retentions on \#30 and fines passed through \#40 were discarded.

Loss on drying (LOD) was noted after each stage of pellet preparation at $105^{\circ} \mathrm{C}$ using suitable moister analyzer. LOD should be NMT $5 \%$ for drug loading and subcoating pellets and NMT 3\% w/w for enteric coating pellets. Dried pellets were stored in suitable container with doublelined LDPE triple-laminated aluminum bags with silica gel desiccant and characterized its properties. With regard to the final dosage form, the multipellets are usually formulated into single-unit dosage forms such as filling them into hard gelatin capsules and evaluated for in vitro drug release study.

\section{Pellets characterization}

Pellet flowability

Angle of repose $(\theta)$ was assessed to know the flowability of pellets by a fixed funnel method, which was essential to the proper scale-up capsule filling. Tapped and bulk density of the pellets was determined using Tap Density Tester. Two other parameters, compressibility index and Hausner's ratio, were also measured to determine the flowability of the pellets and to compare with the prediction made by angle of repose. The compressibility index has been used as an indirect measure of moisture

Table 1: Formulations of omeprazole magnesium (mg/capsule)

\begin{tabular}{|c|c|c|c|c|c|c|c|c|}
\hline Ingredients & F1 & F2 & F3 & F4 & F5 & F6 & F7 & F8 \\
\hline \multicolumn{9}{|l|}{ Core material } \\
\hline Sugar spheres & 22.0 & 22.0 & 22.0 & 22.0 & 22.0 & 22.0 & 22.0 & 22.0 \\
\hline \multicolumn{9}{|l|}{ Drug layering (110\% w/w build up) } \\
\hline Omeprazole magnesium & 20.6 & 20.6 & 20.6 & 20.6 & 20.6 & 20.6 & 20.6 & 20.6 \\
\hline HPMC E5 premium & 5.0 & 5.0 & 5.0 & 5.0 & 5.0 & 5.0 & 5.0 & 5.0 \\
\hline $\mathrm{NaOH}$ & 0.3 & 0.3 & 0.3 & 0.3 & 0.5 & 0.5 & 0.5 & 0.5 \\
\hline Polysorbate 80 & 0.2 & 0.2 & 0.2 & 0.2 & 0.2 & 0.2 & 0.2 & 0.2 \\
\hline Purified water (18\% w/w of solids) & QS & QS & QS & QS & QS & QS & QS & QS \\
\hline \multicolumn{9}{|l|}{ Subcoating ( $60 \% \mathrm{w} / \mathrm{w}$ build up) } \\
\hline Hydroxypropyl cellulose & 1.0 & 1.0 & 1.5 & 2.0 & 2.5 & 3.0 & 3.5 & 5.0 \\
\hline Talc & 7.0 & 7.0 & 7.0 & 7.0 & 7.0 & 7.0 & 7.0 & 9.0 \\
\hline Magnesium stearate & 0.5 & 0.5 & 0.5 & 0.5 & 0.5 & 0.5 & 0.5 & 0.5 \\
\hline Purified water (12\% w/w of solids) & QS & QS & QS & QS & QS & QS & QS & QS \\
\hline \multicolumn{9}{|l|}{ Enteric coating ( $80 \% \mathrm{w} / \mathrm{w}$ build up) } \\
\hline Imwitor $900 \mathrm{~K}$ & 0.5 & 0.5 & 0.5 & 0.5 & 0.5 & 0.5 & 0.5 & 1.0 \\
\hline Eudragit L30 D55 & 31.1 & 31.1 & 31.1 & 31.1 & 31.1 & 31.1 & 31.1 & 40.0 \\
\hline TEC & 10.0 & 10.0 & 10.0 & 10.0 & 10.0 & 10.0 & 10.0 & 10.0 \\
\hline Purified water (15\% w/w solids) & QS & QS & QS & QS & QS & QS & QS & QS \\
\hline
\end{tabular}

QS: Quantity sufficient, TEC: Triethyl citrate, HPMC: Hydroxypropyl methylcellulose 
Table 2: Process parameters of fluid bed processor

\begin{tabular}{llll}
\hline Parameters & $\begin{array}{l}\text { Drug } \\
\text { layering }\end{array}$ & Subcoating & $\begin{array}{l}\text { Enteric } \\
\text { coating }\end{array}$ \\
\hline Inlet temperature $\left({ }^{\circ} \mathrm{C}\right)$ & $44-47$ & $50-55$ & $35-45$ \\
Product temperature $\left({ }^{\circ} \mathrm{C}\right)$ & $20-35$ & $35-45$ & $28-35$ \\
Exhaust temperature $\left({ }^{\circ} \mathrm{C}\right)$ & $33-36$ & $33-43$ & $25-34$ \\
Drive speed (CFM) & $25-40$ & $25-35$ & $30-40$ \\
Atomization (Barr) & $0.8-1.0$ & $0.8-1.8$ & $0.8-3.5$ \\
Peristaltic pump speed & $2-15$ & $2-15$ & - \\
Spray rate (g/min) & $2-6$ & $2-8$ & $2-8$ \\
Wurster height $(\mathrm{cm})$ & - & - & $2.5-5.0$ \\
\hline
\end{tabular}

content, bulk density, size, shape, surface area, and cohesiveness of pellets. The percentage of compressibility was determined using Carr's compressibility index formula and Hausner's ratio from the ratio of bulk and tapped densities as per USP [11,12].

Fourier transform infrared (FTIR) spectrophotometer

One milligram each of the pure and formulated drug was taken and mixed separately with $10 \mathrm{mg}$ of dry powdered potassium bromide. The powdered mixture was taken in a diffuse reflectance sampler, and the spectrum was recorded by scanning in the wavelength region of 4000$400 / \mathrm{cm}$ using a Jasco FTIR spectrophotometer (Jasco, Essex, UK). The IR spectrum of the drug was compared with that of the physical mixture to check for any possible drug-excipient interaction.

Differential scanning calorimeter (DSC)

DSC thermograms of the pure and formulated drug were recorded on the DSC, Perkin-Elmer Pyris, USA. Samples (2-5 mg) were sealed into aluminum pans and scanned at a heating rate of $10^{\circ} \mathrm{C} / \mathrm{min}$ over a temperature range of $0-400^{\circ} \mathrm{C}$ under a nitrogen gas stream.

Scanning electronic microscopy (SEM)

The micrographs of the coated pellets were taken with a scanning electron microscopy (Hitachi, Model: S-3400 N, Tokyo, Japan) to study the surface morphology of the pellets.

The pellets were mechanically sputtered with gold for 5 min by a sputter.

\section{Evaluation parameters of capsules}

Evaluation parameters of capsules such as lock length, average weight, average weight of net contents, and uniformity of weight were determined as per the USP guidelines [11].

Assay

Twenty capsules were accurately weighed, and contents of the capsules were transferred into $100 \mathrm{ml}$ volumetric flask. The solution was made up with pH 6.8 phosphate buffer and sonicated for 20 min for uniform dissolving of the drug. Then, the absorbance value was noted using UVVIS spectrophotometer at $222 \mathrm{~nm}$.

\section{Dissolution studies}

The dissolution guidelines for omeprazole magnesium containing formulations in the monograph of USP35/NF30 $[2,11]$ is for delayed release capsules of omeprazole. Therefore, the dissolution strategies [9] were adopted for this project, which was studied using the DISSO 2000 (Lab India, Mumbai, India), the USP dissolution apparatus II (paddle method) at the stirring rate of $100 \mathrm{rpm}$, and temperature maintained at $37 \pm 0.5^{\circ} \mathrm{C}$. The capsules filled with the coated pellets were taken out and placed in $500 \mathrm{~mL}$ of $0.1 \mathrm{~N} \mathrm{HCl}$ with the sinkers stirring at $100 \mathrm{rpm}$ for $2 \mathrm{~h}$, and then, the medium was replaced with $900 \mathrm{~mL}$ of phosphate buffer at $\mathrm{pH} 6.8$ to continue the dissolution study for another $1 \mathrm{~h}$ to examine the in vitro release pattern of the pellets. Samples of $5 \mathrm{~mL}$ were collected at the intervals of 5, 10,15, 20, 30, 45, and $60 \mathrm{~min}$ from each vessel and filtered through a $0.2-\mu \mathrm{m}$ membrane filter into a test tube. The medium in each dissolution vessel was replenished after each withdrawal. Samples were then assayed with UV spectrophotometer at $222 \mathrm{~nm}$ and converted into the cumulative amount of omeprazole magnesium release for the time point through utilization of the established standard curves in these two media, $0.1 \mathrm{~N}$ $\mathrm{HCl}$ and $\mathrm{pH} 6.8$ phosphate buffer. The dissolution experiments were conducted in triplicate.

\section{Stability studies}

Stability studies were carried out on the optimized formulation, as per the ICH guidelines. The capsules filled with coated pellets were packed in HDPE bottle and stored at $40^{\circ} \mathrm{C} / 75 \% \mathrm{RH}$ for 6 months as per the ICH guidelines. During storage, the samples were monitored for appearance. Drug content and dissolution rate of the pellets were measured at initial, 1,3 , and 6 months.

\section{RESULTS}

\section{Preformulation studies}

In preformulation studies, solubility analysis is important because the drug has to dissolve in the solvents and also in the dissolution medium used. Omeprazole magnesium was found to be freely soluble in methanol and ethanol, sparingly soluble in isopropanol and acetone, practically insoluble in water. The solubility of omeprazole magnesium in different solvents was comparatively represented as purified water $(0.06 \mathrm{mg} / \mathrm{mL})<\mathrm{pH} 7.4$ phosphate buffer $(0.21 \mathrm{mg} / \mathrm{mL})<\mathrm{pH} 6.8$ phosphate buffer $(0.27 \mathrm{mg} / \mathrm{mL})$. The relative standard deviation for the solubility of omeprazole in each solvent was determined to be $<5 \%$, indicating an accurate assessment.

The results of compatibility studies reveal that the omeprazole magnesium was not compatible with the excipients. In physical compatibility studies, there was no change in color, odor, and physical state of the drug in open environment. Chemical compatibility studies were performed to know the compatibility of the drug with excipients in open and closed environment. The total \% impurity range, initially at $2-8^{\circ} \mathrm{C}$, was $0.03-0.09$ and after accelerated conditions at $40^{\circ} \mathrm{C} / 75 \% \mathrm{RH}$ was $0.04-0.14$. Around $0.01-0.05$ drop in potency was observed after 4 weeks of direct exposure.

\section{Formulation and characterization of enteric coated pellets \\ Flow properties}

The delayed release pellets of omeprazole magnesium were prepared using pelletization method. The pellets of different formulations were evaluated for bulk and tapped density. The results are shown in Table 3. Bulk density for delayed release pellets F1-F8 was found to be between $0.921 \mathrm{~g} / \mathrm{cc}$ and $0.948 \mathrm{~g} / \mathrm{cc}$. Tapped density for F1-F8 was found to be between $0.680 \mathrm{~g} / \mathrm{cc}$ and $1.006 \mathrm{~g} / \mathrm{cc}$. The values obtained were within the acceptable range, and there was no large difference noticed. With this result, we can calculate the \% compressibility of the powder using Carr's compressibility index and Hausner's ratio. Compressibility index was found to be in the range of 12.09-12.84 indicating good flow. Hence, all formulations exhibit good compressibility. Hausner's ratio for delayed release pellets was found to be between 1.02 and 1.05 . With this, the pellets were found to be free flowing. Angle of repose for delayed release pellets was found to be between $17.6^{\circ}$ and $20.25^{\circ}$ which was within specified limits of 15-30 and the type of flow was good.

\section{FTIR spectrophotometer}

The individual IR spectra of the pure form of omeprazole magnesium and formulation of drug with excipients of delayed release pellet are shown in Fig. 1. All the characteristic peaks of omeprazole magnesium at 3431/cm (N-H, stretching), 3071/cm (Aromatic C-H stretch), 2943 and 2094/cm (C-H, stretch), 1621/cm (C=C stretch), 1587/cm (C=N, stretch), 1510/cm ( $\mathrm{CH}_{2}$ bending), 1402/cm ( $\mathrm{CH}$ Bending), 1157/ $\mathrm{cm}(\mathrm{C}=0$ Stretch), $1075 / \mathrm{cm}$ (C=S Stretch), and 966,885 , and 821/cm (C-H Bending) were present in spectra, thus indicating compatibility between drug and excipients. It shows that there was no significant change in the chemical integrity of the drug. 
Table 3: Flow properties of all formulations*

\begin{tabular}{|c|c|c|c|c|c|}
\hline Formulation code & Angle of repose $(\theta)$ & Bulk density (g/cc) & Tapped density (g/cc) & Hausner's ratio & Carr's index (\%) \\
\hline $\mathrm{F} 1$ & $29.1 \pm 0.23$ & $0.940 \pm 0.06$ & $0.989 \pm 0.12$ & $1.02 \pm 0.23$ & $4.98 \pm 0.12$ \\
\hline F2 & $28.5 \pm 0.32$ & $0.945 \pm 0.065$ & $1.003 \pm 0.13$ & $1.01 \pm 0.22$ & $4.80 \pm 0.12$ \\
\hline F3 & $28.0 \pm 0.39$ & $0.948 \pm 0.069$ & $1.005 \pm 0.15$ & $1.05 \pm 0.26$ & $4.78 \pm 0.15$ \\
\hline F4 & $27.1 \pm 0.42$ & $0.942 \pm 0.071$ & $1.006 \pm 0.16$ & $1.023 \pm 0.22$ & $5.011 \pm 0.22$ \\
\hline F5 & $26.8 \pm 0.45$ & $0.929 \pm 0.075$ & $1.002 \pm 0.12$ & $1.03 \pm 0.34$ & $4.40 \pm 0.25$ \\
\hline F6 & $26.0 \pm 0.51$ & $0.929 \pm 0.078$ & $0.87 \pm 0.13$ & $1.05 \pm 0.37$ & $4.28 \pm 0.18$ \\
\hline F7 & $25.8 \pm 0.59$ & $0.928 \pm 0.052$ & $0.68 \pm 0.15$ & $1.05 \pm 0.39$ & $5.12 \pm 0.20$ \\
\hline Innovator & $38.0 \pm 0.33$ & $0.406 \pm 0.023$ & $0.586 \pm 0.013$ & $1.43 \pm 0.22$ & $4.11 \pm 0.23$ \\
\hline
\end{tabular}

${ }^{*}$ All values are expressed as mean $\pm S E, n=3$. SE: Standard error

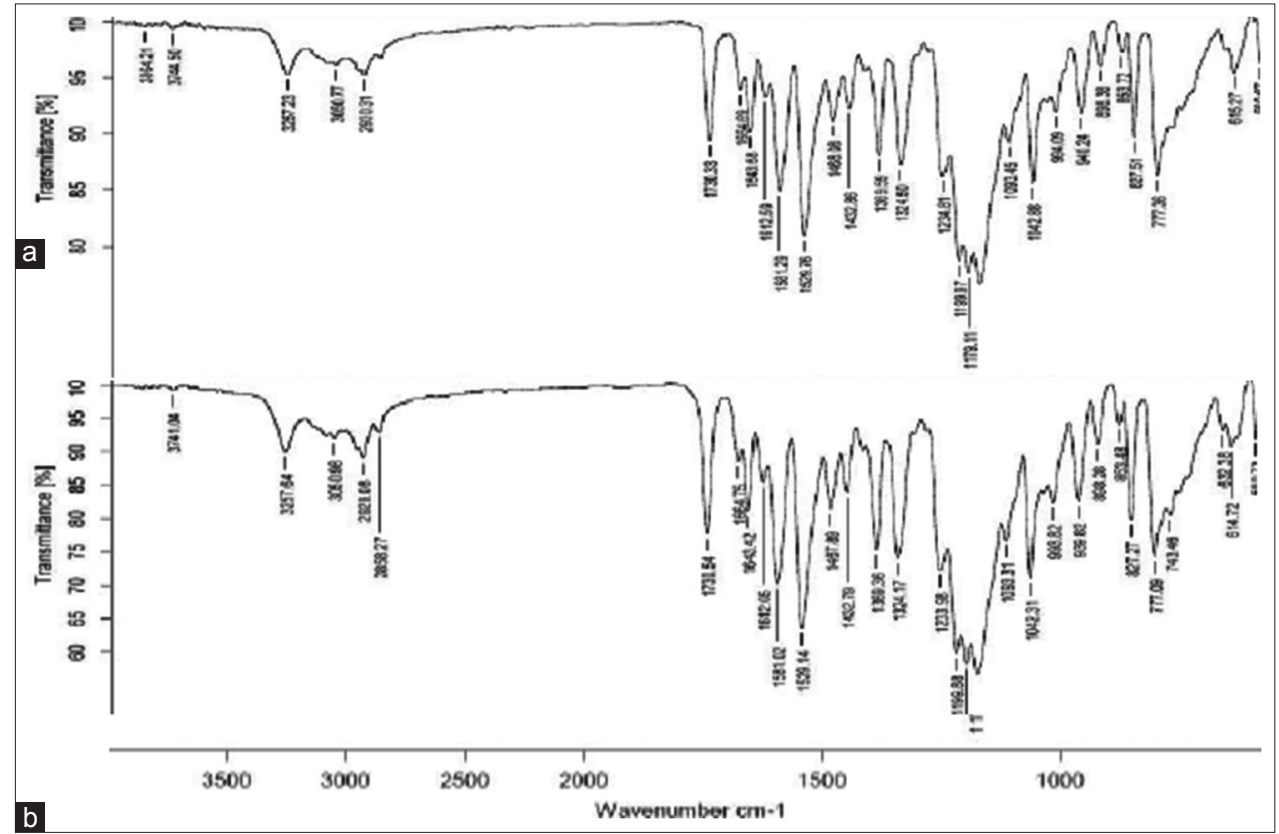

Fig. 1: Fourier transform infrared spectra of (a) pure drug and (b) formulated drug

DSC

The DSC thermograms of pure drug and layered pellets of omeprazole magnesium were conducted to explore the melting activities of drug as shown in Fig. 2. DSC analysis showed a sharp endothermic peak at $152^{\circ} \mathrm{C}$. The melting range of omeprazole magnesium was 150$155^{\circ} \mathrm{C}$ as per the United States Pharmacopeia [2]. The formulation of omeprazole magnesium in the layered pellets exhibited a shift of the endodermic peak to $151.8^{\circ} \mathrm{C}$. Hence, the results prove that there was no incompatibility between the drug and excipients [18].

SEM

SEM images are taken to evaluate the shape of the pellets and dimensions as well. Hence, the shape of the pellets was spherical, uniform in appearance, and with slightly rough surface. It is shown in Fig. 3.

\section{Evaluation parameters}

The lock length of capsules was determined using calibrated Vernier calipers, and the length of lock ranges from 14 to $16 \mathrm{~mm}$. Hence, all the formulations follow the same range. The average weight, content uniformity, and assay of all the formulations were performed, and the results are shown in Table 4. The assay of optimum formulation F8 shows percentage purity up to $99.85 \%$ which is underspecified range.

Dissolution studies

The in vitro drug release study was carried out using USP dissolution apparatus II (Paddle type), and the dissolution profile of all the delayed release formulations, i.e., (F1-F8) is shown in Fig. 4. From the results, formulation $\mathrm{F} 1$ to $\mathrm{F} 4$ showed their release profile up to $69-72 \%$ only. It is because of the absence of anti-agglomerate agent and low amount of disintegrant in drug layering of the formulation. The formulations F5, F6, and F7 contain super disintegrant HPC-L which fastens the release of drug from the formulations. F5 contains less amount of HPC-L when compared to F6 and F7. However, formulations F6 and F7 had less weight gain. Formulation F8 shows 100\% drug release, which is better drug release than the above formulations due to efficient amount of eudragit and disintegrant. The dissolution profile of formulation F8 was compared with innovator product (Equate), which is shown in Fig. 5, and dissolution efficiency (DE) values were calculated as per Khan [13]; the $\mathrm{DE}_{30}$ relates to the dissolution of the drug from a particular formulation after $30 \mathrm{~min}$. $\mathrm{DE}_{30}$ values of formulation F8 and innovator were $62.75 \pm 0.81$ and $64.01 \pm 1.02$, respectively.

The release profiles of delayed release pellets of omeprazole magnesium of all formulations are shown in Table 5. The release kinetics of formulations from F1 to F8 follow zero-order drug release because the values of regression coefficient obtained for zero-order release profiles $(r \geq 0.977)$ are higher as compared to first-order plots $(r \leq 0.723)$ and Higuchi plots show " $r$ " value in between 0.427 and 0.725 . The Korsmeyer-Peppas value " $r$ " was found to be between 0.837 and 0.969 and the n value was found to be $>1$. The magnitude of the exponent " $n$ " indicates the release mechanism of drug. Hence, it follows super case II transport in non-Fickian diffusion [14-16].

In dissolution profile comparisons, dissimilarity factor (f1) and 
Table 4: Evaluation parameters of capsules

\begin{tabular}{lllll}
\hline Formulation code & Lock length* $^{(\mathbf{m m})}$ & Average weight of capsules** $\mathbf{( m g )}$ & Average weight of net contents** $(\mathbf{m g})$ & Assay* $(\%)$ \\
\hline F1 & $14.44 \pm 0.11$ & $174.8 \pm 0.10$ & $136.0 \pm 0.02$ & $94.0 \pm 0.12$ \\
F2 & $14.45 \pm 0.12$ & $175.9 \pm 0.12$ & $134.0 \pm 0.03$ & $95.0 \pm 0.15$ \\
F3 & $14.44 \pm 0.13$ & $177.2 \pm 0.10$ & $135.0 \pm 0.10$ & $95.6 \pm 0.23$ \\
F4 & $14.39 \pm 0.10$ & $174.0 \pm 0.15$ & $136.5 \pm 0.11$ & $96.5 \pm 0.28$ \\
F5 & $14.44 \pm 0.12$ & $175.0 \pm 0.13$ & $136.0 \pm 0.08$ & $96.6 \pm 0.30$ \\
F6 & $14.44 \pm 0.11$ & $174.0 \pm 0.11$ & $137.1 \pm 0.05$ & $97.0 \pm 0.23$ \\
F7 & $14.45 \pm 0.11$ & $174.9 \pm 0.10$ & $137.3 \pm 0.06$ & $98.0 \pm 0.22$ \\
F8 & $14.45 \pm 0.12$ & $174.9 \pm 0.11$ & $137.3 \pm 0.10$ & $99.5 \pm 0.23$ \\
\hline
\end{tabular}

*All values are expressed as mean $\pm S E, n=5$; **All values are expressed as mean $\pm S E, n=20$. SE: Standard error

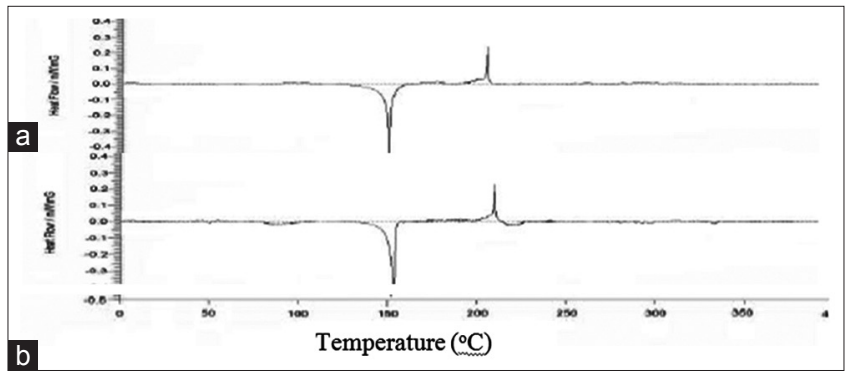

Fig. 2: Differential scanning colorimeter thermograms of (a) pure drug and (b) formulated drug

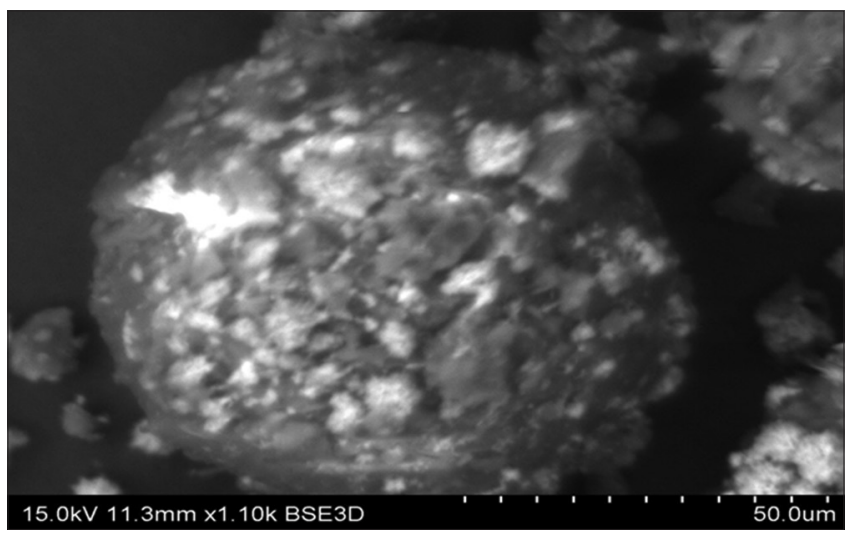

Fig. 3: Scanning electron microscopy image of omeprazole magnesium pellets

similarity factor (f2) were calculated $[17,28]$ to assure performance similarity of the two products, and it is important to know how the two dissolution curves are close to each other and also to have a measure which is sensitive to large differences at any particular time point. The comparison of in vitro dissolution profiles of formulation F8 and innovator product (Equate) was carried out in $\mathrm{pH} 6.8$ phosphate buffer. The values ( $f 1=8.75 \pm 1.4$ and $f 2=52.09 \pm 1.2$ ) show that there was a similarity between both the profiles. The similarity factor fits result between 0 and 100 . Two drug release profiles are similar if the $f 2$ is $\geq 50$ and $\mathrm{f} 1$ values are $\leq 15$. Therefore, it may be concluded that formulation F8 has shown similar drug release characteristic when compared to the innovator product (Equate). Hence, it was selected as the optimized formulation

Statistical analysis by independent t-test $[14,28]$ was performed to test whether the difference in mean dissolution efficiency values at $30 \mathrm{~min}$ in pH 6.8 phosphate buffer observed between formulation F8 and innovator product was significant or not. The analysis revealed that the difference between the methods was statistically significant at $\mathrm{p}<0.05$. The absolute value of the calculated $t$ is smaller than critical value $(2.10<2.77)$, so the means are not significantly different. Therefore,

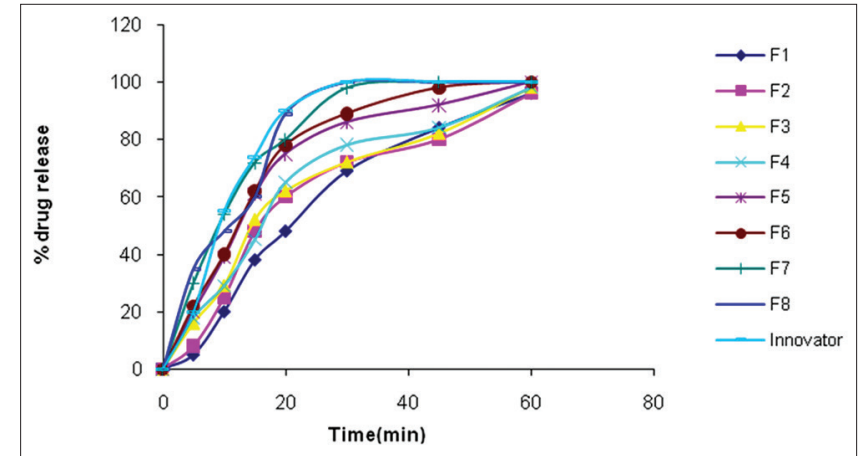

Fig. 4: Dissolution profiles of all formulations omeprazole magnesium pellets in $\mathrm{pH} 6.8$ phosphate buffer

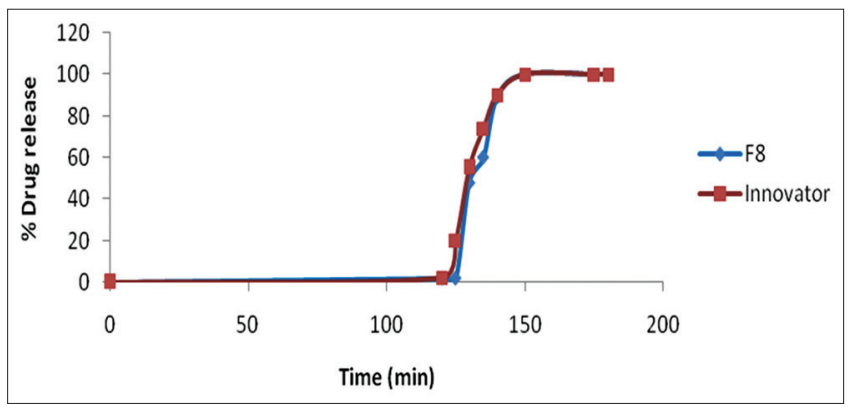

Fig. 5: Dissolution profiles optimum formulation (F8) with innovator (equate) in $0.1 \mathrm{~N} \mathrm{HCl}$ and $\mathrm{pH} 6.8$ phosphate buffer

there was no difference between formulation F8 and innovator.

\section{Stability studies}

Accelerated stability test was conducted for the optimized formulation for 6 months at $40^{\circ} \mathrm{C} / 75 \% \mathrm{RH}$. The results showed that there was no change in the formulated pellets during the storage period. The results are shown in Table 6.

\section{DISCUSSION}

In this study, the delayed release pellets of poorly water-soluble omeprazole magnesium were prepared using fluid bed processor because the drug showed poor flow property. Saturation solubility of omeprazole magnesium was conducted at stomach and small intestine $\mathrm{pH}$ and observed that relative sink condition $\left(\mathrm{C}_{\mathrm{S}} / \mathrm{C}_{\mathrm{D}}\right)$ was high at small intestine $\mathrm{pH}$. The gastric stability and drug release of uncoated pellets were very poor, demonstrating that all of the drugs were degraded when pellets were immersed in acid medium for $10 \mathrm{~min}$. Fang et al. are observed that the pellets were coated with film-forming agents, and the films of coated pellets were excellent without damage in acidic medium and had better stability in neutral/alkaline medium and improved oral bioavailability of the drug [3,32,33]. 
Table 5: Pearson's correlation coefficient (r), following linear dissolution data and release exponent (n)*

\begin{tabular}{|c|c|c|c|c|c|}
\hline \multirow[t]{2}{*}{ Formulations } & \multirow{2}{*}{$\begin{array}{l}\text { Zero order } \\
\text { r }\end{array}$} & \multirow{2}{*}{$\begin{array}{l}\text { First order } \\
\mathbf{r}\end{array}$} & \multirow{2}{*}{$\begin{array}{l}\text { Higuchi } \\
\text { r }\end{array}$} & \multicolumn{2}{|c|}{ Korsmeyer-Peppas } \\
\hline & & & & $\mathbf{r}$ & $\mathbf{n}$ \\
\hline F1 & 0.991 & 0.723 & 0.451 & 0.969 & 1.186 \\
\hline $\mathrm{F} 2$ & 0.987 & 0.685 & 0.499 & 0.953 & 1.149 \\
\hline F3 & 0.988 & 0.641 & 0.584 & 0.926 & 1.065 \\
\hline F4 & 0.989 & 0.640 & 0.596 & 0.924 & 1.091 \\
\hline F5 & 0.983 & 0.614 & 0.662 & 0.896 & 1.019 \\
\hline F6 & 0.983 & 0.609 & 0.699 & 0.890 & 1.101 \\
\hline F7 & 0.977 & 0.570 & 0.723 & 0.842 & 1.079 \\
\hline F8 & 0.992 & 0.567 & 0.723 & 0.837 & 1.073 \\
\hline Innovator & 0.984 & 0.598 & 0.745 & 0.867 & 1.117 \\
\hline
\end{tabular}

*All values are expressed as standard mean $n=3$

Table 6: Stability studies for formulation $\mathrm{F} 8$ at $40^{\circ} \mathrm{C} / 75 \% \mathrm{RH}$

\begin{tabular}{llll}
\hline Storage condition & Description & Dissolution (\%) & Moisture Content (\%w/w) \\
\hline Initial & Complies & 100.00 & 1.85 \\
$1^{\text {st }}$ month & Complies & 100.00 & 1.89 \\
$3^{\text {rd }}$ month & Complies & 99.99 & 1.92 \\
$6^{\text {th }}$ month & Complies & 99.81 & 1.98 \\
\hline
\end{tabular}

The drug-loaded pellets were coated with hypromellose as a filmforming agent [20] and HPC-L as a binder or disintegrant in the powder layering process on spherical cores to fabricate round spheres and rapid dissolution $[6,19]$. In vitro drug release profiles of all formulations are shown in Fig. 4, and from the formulations F1-F4, the absence of talc leads to agglomeration of the pellets which led to improper drug release and low amount of disintegrant led to less dissolution. Whereas, the formulations F5, F6, and F7 contain super disintegrant HPC-L which has fasten the release of drug from the formulations. An increased coating level led to an amplified extent of diffusion pathways and increasing duration of the drug to diffuse through the coating membrane [3].

Eudragit L30 D-55 is the aqueous dispersion of anionic polymers with methacrylic acid as a functional group used as enteric film coating for drug and significantly influences the drug stability and bioavailability due to the interaction of the free carboxyl groups and the drug. It was effective and stable enteric coatings with a fast dissolution in the upper bowel and easily redispersed into water with the help of small amounts of alkali resulting in redispersed latex with $\mathrm{pH} 2-3$. The polymer at lower $\mathrm{pH}$ and the carboxyl groups are not ionized and render them insoluble ' $[21,22]$. At higher $\mathrm{pH}(\geq 5)$, the carboxylic groups became ionized, causing polymer to dissolve and specifically drug delivered in intestinal site [3-5]. Hence, formulation F8 shows 100\% drug release in $30 \mathrm{~min}$ due to efficient amount of Eudragit and disintegrant.

Triethyl citrate (TEC) is a plasticizer strongly affecting the drug release from the coated pellets due to the presence of higher hydrophilicity of TEC, and the films took up water more rapidly, rendering an increase in the permeability of films [23]. When plasticizer is added to the film, it provoked greater mobility of the polymer chains by replacing polymerpolymer interactions by polymer-plasticizer interactions [24]. TEC was a better and more compatible plasticizer for Eudragit dispersion to render a formation of more uniform and continuous film, hindering the leaching out of plasticizer. Thus, the pellets coated by dispersion plasticized by TEC were more beneficial to the gastric stability of omeprazole magnesium pellets [3].

All formulation results were compared with innovator, and finally, F8 formulation is reported as optimum formulation. Based on the investigation that the efficient amount of anti-agglomerant (talc) and super disintegrant (HPC-L) is the main reason for the release of the drug in intestine $\mathrm{pH}$. The calculation of the release kinetics showed that the most suitable kinetic model was zero-order, as demonstrated in Table 3. As the mechanism of omeprazole magnesium release from the delayed release pellets is not well-known, it was calculated using the Korsmeyer-Peppas model, which relates drug release exponentially to the elapsed time. The model showed that $n>1$ means that it follows super case II transport in non-Fickian diffusion. In super case II transport, the rate of solvent diffusion is greater and is the determining factor of the diffusion $[25,26]$.

Statistically, independent t-tests were performed, and there was no significance difference observed in between optimized formulation (F8) and innovator product (Equate) dissolution profile at $\mathrm{p}<0.05$.

FTIR and DSC studies were conducted for optimized formula to prove that the formula was not having incompatibility between the drug and excipients. A comparison between IR spectra of the pure drug and the formulation of drug with the excipients, it was observed that all the characteristic peaks of omeprazole magnesium present in the combination spectra as well; thus indicating the compatibility of the drug with excipients used. In DSC thermograms, the melting activities were found to be very close to authentic range of official standard $[11,18]$ for both pure and formulated drugs.

The SEM image illustrates the surface morphology of the pellets. The ideal pellet shape for the formulation is a spherical form to facilitate homogeneous diffusion of an active ingredient and proper pellet coating [29]. The prepared pellets were free flowing, white in color, uniform in appearance, and with slightly rough surface. The drug content was consistent in all formulations.

After storage for 6 months at $40^{\circ} \mathrm{C} / 75 \% \mathrm{RH}$, the coated pellets significantly improved the drug stability [34]. It was attributed to the decreased moisture absorption that participated a key role in the stability of omeprazole magnesium in optimized formulation [30,31]. The enteric polymer Eudragit, due to the presence of an ester structure, was liable to hydrolysis in humid conditions, affecting the enteric protection in acid medium.

\section{CONCLUSION}

The formulations of delayed release pellets of omeprazole magnesium were developed by enteric film coating process varying the compositions of drug loading, barrier coating, and enteric coating. It was prepared by the drug layering technique using fluid bed processor. Whereas, omeprazole magnesium was degraded in stomach $\mathrm{pH}$, so it was formulated as delayed release dosage form to absorb in intestine 
$\mathrm{pH}$. The dissolution profile of optimized formulation (F8) contains the efficient amount of talc, hydroxypropyl cellulose-L, and Eudragit L30 D55 which leads to effective release of drug in $30 \mathrm{~min}$ in $\mathrm{pH} 6.8$ phosphate buffer. FTIR and DSC studies were proved that there was no incompatibility between the drug and excipients. The SEM image illustrates the surface morphology of the pellets. It was concluded that the final formulation (F8) shown good similarity with innovator and the results of the accelerated stability studies revealed that storage conditions were excellent.

\section{AUTHOR'S CONTRIBUTION}

Dr. Varalakshmi M made substantial contributions to conception, design, analysis, and interpretation of data and participate in drafting the article or revising it critically for important intellectual content. Rezwana SK participates in design, acquisition of data, and participated in data analysis.

\section{CONFLICTS OF INTEREST}

The authors declared no conflicts of interest.

\section{REFERENCES}

1. Dash SMurthy PNNath LChowdhury P1. McTavish D, Buckley MM, Heel RC. Omeprazole. An updated review of its pharmacology and therapeutic use in acid-related disorders. Drugs 1991;42:138-70

2. The United States Pharmacopeial Convention, Official Monographs/ Omeprazole USP 35-NF 30; 2012. p. 4115-6.

3. Fang Y, Wang G, Zhang R, Liu Z, Liu Z, Wu X, et al. Eudragit L/ HPMCAS blend enteric-coated lansoprazole pellets: Enhanced drug stability and oral bioavailability. AAPS Pharm Sci Tech 2014;15:513-22.

4. de Oliveira HP, Albuquerque JJ Jr., Nogueiras C, Rieumont J. Physical chemistry behavior of enteric polymer in drug release systems. Int $\mathrm{J}$ Pharm 2009;366:185-9.

5. Missaghi S, Young C, Fegely K, Rajabi-Siahboomi AR. Delayed release film coating applications on oral solid dosage forms of proton pump inhibitors: Case studies. Drug Dev Ind Pharm 2010;36:180-9.

6. Rowe RC, Sheskey PJ, Qulnn ME. Hydroxypropyl Cellulose, Handbook of Pharmaceutical Excipients. $6^{\text {th }}$ ed. Washington, DC: Pharmaceutical Press, An imprint of RPS (Royal Pharmaceutical Society of Great Britain) Publishing; 2009. p. 317-21.

7. Isaac GS, Axel K. Encyclopedia of Pharmaceutical Technology. $3^{\text {rd }}$ ed., Vol. 1. New York: Informa Healthcare; 2007. p. 2651-63.

8. He W, Tian Z, Yang M, Fan J, Zhang S, Guan P, et al. A comparative study of the effect of different alkaline stabilizers on physicochemical properties of lansoprazole in formulation. Asian J Pharm Sci 2011;6:89-100.

9. He W, Yang M, Fan JH, Feng CX, Zhang SJ, Wang JX, et al. Influences of sodium carbonate on physicochemical properties of lansoprazole in designed multiple coating pellets. AAPS Pharm Sci Tech 2010;11:1287-93.

10. Melegari C, Bertoni S, Genovesi A, Hughes K, Rajabi-Siahboomi AR, Passerini $\mathrm{N}$, et al. Ethylcellulose film coating of guaifenesin-loaded pellets: Amcomprehensive evaluation of the manufacturing process to prevent drug migration. Eur J Pharm Biopharm 2016;100:15-26.

11. Convention, Inc. US P32/NF27. Chapter 711: Dissolution, Chapter 786: Particle Size Distribution, Chapter 1174: Powder Flow, Rockville MD: Convention, Inc.; 2009. p. 263, 307, 688.

12. Cooper J, Gun C, Carter SJ. Powder Flow and Compaction. Tutorial Pharmacy. New Delhi: CBS Publishers; 1986. p. 211-33.

13. Khan KA. The concept of dissolution efficiency. J Pharm Pharmacol
$1975 ; 27: 48$

14. Dash S, Murthy PN, Nath L, Chowdhury P. Kinetic modeling on drug release from controlled drug delivery system. Acta Pol Pharm 2010;67:217-23.

15. Lokhandwala H. Kinetic modeling and dissolution profiles comparison: An overview. Int J Pharm Biosci 2013;4:728-37.

16. Chuong MC, Palugan L, Su TM, Busano C, Lee R, Di Pretoro G, et al. Formulation of controlled-release capsules of biopharmaceutical classification system i drugs using niacin as a model. AAPS Pharm Sci Tech 2010;11:1650-61.

17. Moore JW, Flanner HH. Mathematical comparison of dissolution profiles. Pharm Tech 1996;20:64-74.

18. Hu Y, Wu G, Gu P, Yang W, Wang C, Ding Z, et al. Thermodynamic models for determination of the solubility of omeprazole in pure and mixture organic solvents from $T=(278.15$ to 333.15$) \mathrm{K}$. J Chem Thermodynamics 2016;94:177-85.

19. Ravella VN, Nadendla RR, Kesari NC. Design and evaluation of sustained release pellets of aceclofenac. J Pharm Res 2013;6:525-31.

20. Friesen DT, Shanker R, Crew M, Smithey DT, Curatolo WJ, Nightingale JA. Hydroxypropyl methylcellulose acetate succinate-based spray-dried dispersions: An overview. Mol Pharm 2008;5:1003-19.

21. Siepmann F, Siepmann J, Walther M, MacRae RJ, Bodmeier R. Blends of aqueous polymer dispersions used for pellet coating: importance of the particle size. J Control Release. 2005;105(3):226-39.

22. Priya YD, Chowdary YA, Murthy TE, Seshagiri B. Design and evaluation of atomoxetine $\mathrm{HCl}$ pellets by MUPS technology. Int $\mathrm{J}$ Pharm Pharm Sci 2014;6:110-5.

23. Lecomte F, Siepmann J, Walther M, MacRae RJ, Bodmeier R. Polymer blends used for the aqueous coating of solid dosage forms: Importance of the type of plasticizer. J Control Release 2004;99:1-13.

24. Laboulfie F, Hmati M, Lamure A, Diguet S. Effect of the plasticizer on permeability, mechanical resistance and thermal behaviour of composite coating films. Powder Technol 2012;23:14-9.

25. Agnes EJ, Ortega GG. Mathematical models and physicochemistry of diffusion. Cad Farm 2003;19:9-19.

26. de Souza DF, Goebel K, Andreazza IF. Development of enteric coated sustained release minitablets containing mesalamine. Braz J Pharm Sci 2013;49:529-36

27. Bussemer T, Bodmeier RA. Drug delivery: Pulsatile systems. Encyclopedia of Pharmaceutical Technology. New York: Marcel Dekker 2007; 1:1287-97.

28. Shah VP, Tsong Y, Sathe P, Liu JP. In vitro dissolution profile comparison statistics and analysis of the similarity factor, $\mathrm{f}_{2}$. Pharma Res 1998;15:889-95.

29. Siepmann F, Siepmann J, Walther M, MacRae RJ, Bodmeier R. Polymer blends for controlled release coatings. J Control Release 2008;125:1-15.

30. Stroyer A, McGinity JW, Leopold CS. Solid-state interactions between the proton pump inhibitor omeprazole and various enteric coating polymers. J Pharm Sci 2006;95:1342-53.

31. He W, Yang M, Fan JH, Feng CX, Zhang SJ, Wang JX, et al. Influences of sodium carbonate on physicochemical properties of lansoprazole in designed multiple coating pellets. AAPS Pharm Sci Tech 2010;11:1287-93.

32. Emara LH, Abdelfattah FM, Taha NF, El-Ashmawy AA, Mursi NM. In vitro evaluation of ibuprofen hot-melt extruded pellets employing different designs of the flow through cell. Int $\mathrm{J}$ Pharm Pharm Sci 2014;6:192-7.

33. Jyothi BJ, Doniparthi J. Multiparticulate drug delivery systems using natural polymers as release retardant materials. Int J Pharm Pharm Sci 2014;6:61-5

34. Vishwas SS, Satish VS, Rupali NK. Formulation optimization of promethazine theoclate immediate release pellets by using extrusion-spheronization technique. Int J Appl Pharm 2018;10:30-5. 